\title{
The Influence of Recipient Smoking Status on Pancreas Transplant Survival and Morbidity
}

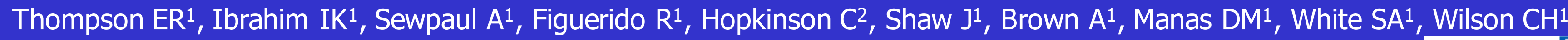
Newcastle University

1 NIHR Blood and Transplant Research Unit, Institute of Transplantation, Freeman Hospital, Newcastle upon Tyne.

2 Statistics and Clinical Studies, NHS Blood and Transplant, UK

\section{Background \& Aims}

- Transplant recipients have a marked increased risk of premature cardiovascular mortality and malignancy in comparison with the general population.

- especially diabetic patients being considered for pancreas transplant.

- In kidney transplantation, recipient smoking is associated with an increased risk of death and graft loss.

- Surprisingly little is known about the impact of smoking following pancreas transplant.

- In an era of organ shortage, identifying patients at risk of early graft loss is vital to aid appropriate allocation.

- We therefore aimed to examine the impact of recipient smoking status on pancreas transplant graft and patient survival.

\section{Methods}

Retrospective data on all UK pancreas transplants from 19842015 was obtained from NHSBT UK transplant registry, $\mathrm{n}=2161$.

- Inclusion Criteria:

- First simultaneous Pancreas Kidney Transplant

Smoking status was classified as non, current or ex-smoker.

Unadjusted graft and patient survival was calculated using Kaplan-Meier plots and compared using the log-rank test.

- Multivariate analysis was performed using Cox proportional hazards regression including the following parameters:

-Recipient age $\quad$ Donor age

-Recipient BMI -Donor BMI

-Mismatch grade -Warm ischaemic time

-Dialysis status pre-transplant $\quad$-Cold ischaemic time

-Donor Type (DCD vs DBD) -\% sensitisation

\section{Results}

Median graft survival was 1114 (0-5171) days (3 years), median patient survival was 1409 (0-9380) days (3.8 years).

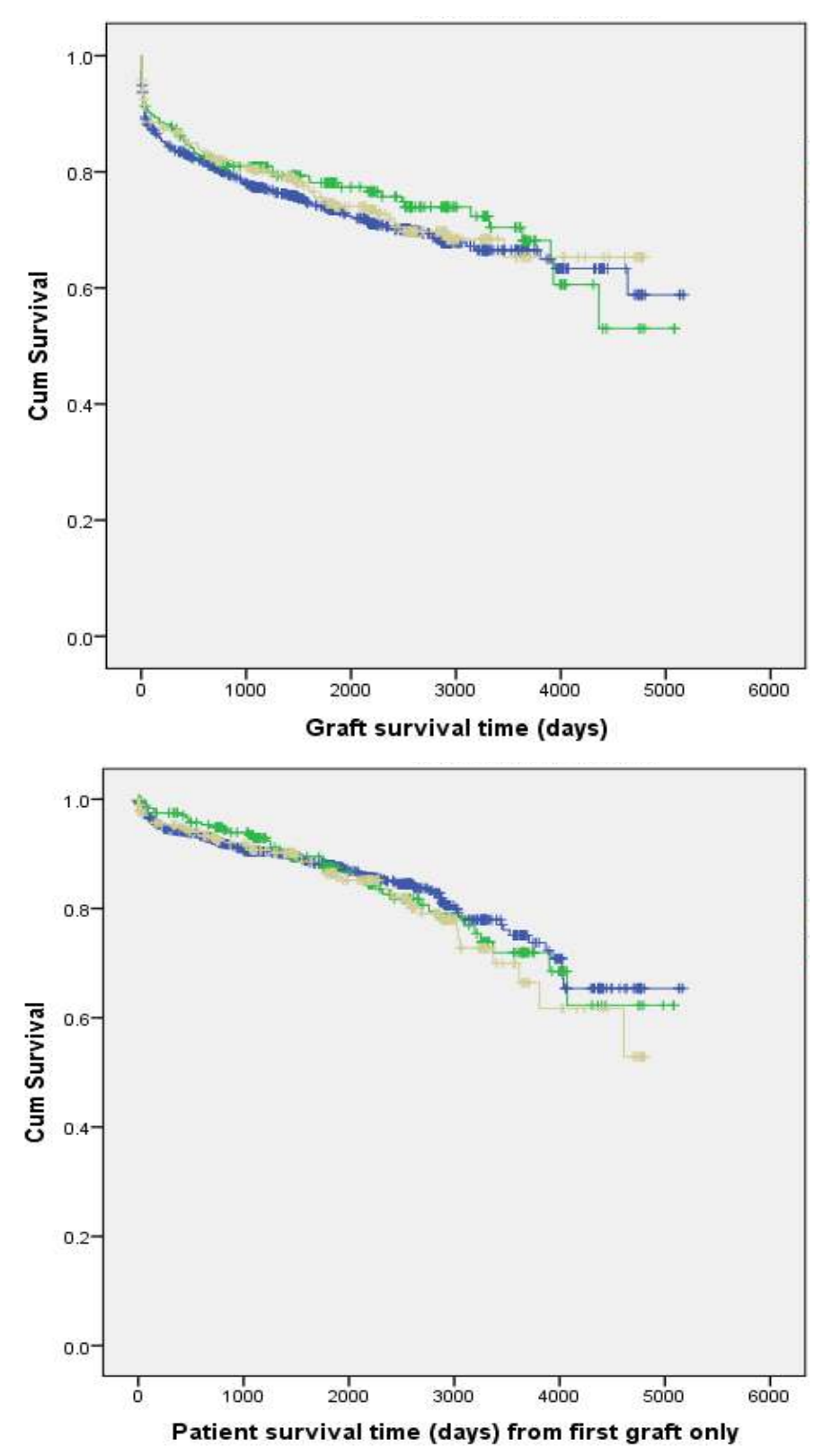

Figure 1: Kaplan-Meier plots reveal no significant difference in graft or patient survival between smoking status groups. Graft survival $p=0.568$, patient survival $p=.651$
The effect of recipient age was analysed in more detail and revealed significantly higher mortality in those recipients over 55 years of age who smoked $(p=0.001)$
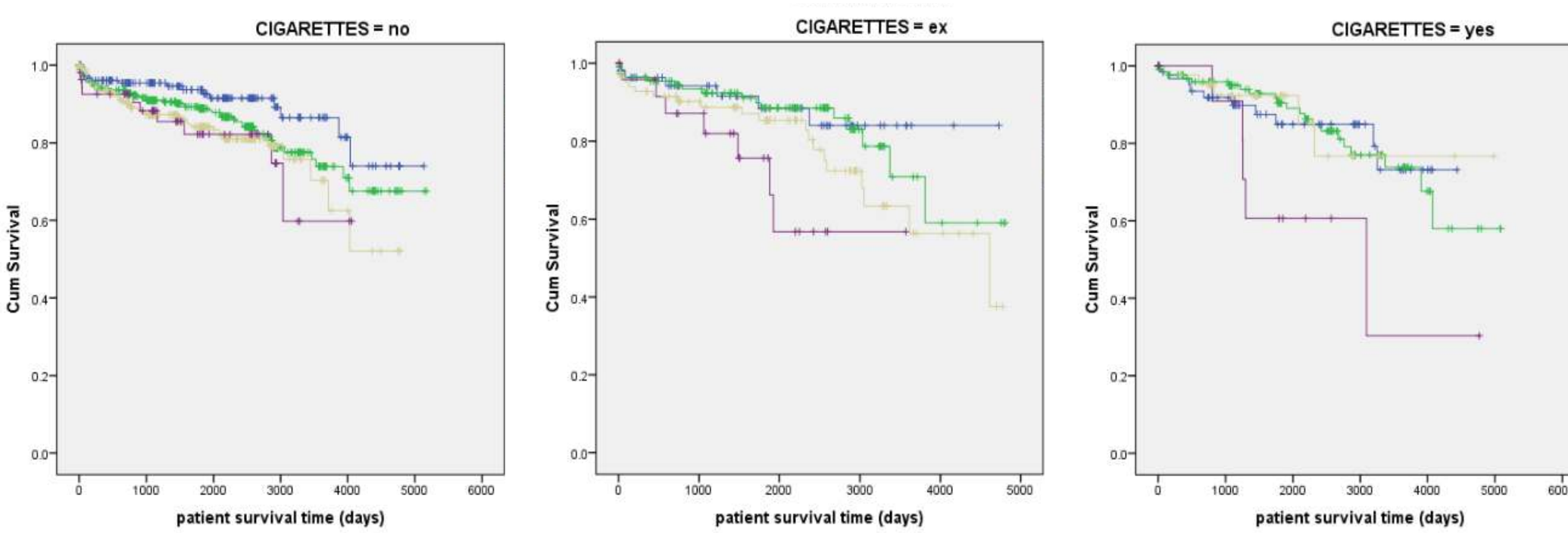

Figure 2: Kaplan-Meier plots survival analysis of smoking status stratified by recipient age.

Multivariate analysis: upon adjustment for confounding variables smoking status remained non significant. Graft survival HR 0.9 (95\% CI 0.6-1.3, p=0.7). Patient survival HR 1.5 (95\% CI 0.8-3.1, $\mathrm{p}=0.3$ ). Prolonged cold ischaemic time, recipient BMI, recipient age, donor age, haemodialysis pre transplant and non favourable HLA mismatch were the most predictive significant variables associated with diminished graft and patient survival.

\begin{tabular}{|c|c|c|c|c|c|c|}
\hline \multirow{2}{*}{ Variable } & \multicolumn{3}{|c|}{ Graft Survival } & \multicolumn{3}{|c|}{ Patient Survival } \\
\hline & $\mathrm{HR}$ & $95 \% \mathrm{CI}$ & $P$ value & $\mathrm{HR}$ & $95 \% \mathrm{CI}$ & $\mathrm{p}$-value \\
\hline Cigarette smoker & 0.884 & $\begin{array}{l}(0.527, \\
1.481)\end{array}$ & 0.639 & 1.542 & $\begin{array}{l}(0.778, \\
3.057)\end{array}$ & 0.214 \\
\hline Recipient BMI & 1.047 & $\begin{array}{l}(1.007, \\
1.089)\end{array}$ & 0.021 & 1.001 & $\begin{array}{l}(0.961, \\
1.063)\end{array}$ & 0.675 \\
\hline Mismatch grade & 0.798 & $\begin{array}{c}(0.382, \\
1.668)\end{array}$ & 0.548 & 2.173 & $\begin{array}{l}(1.037, \\
4.555)\end{array}$ & 0.040 \\
\hline$\underset{t x}{\text { Haemodialysis pre- }}$ & 1.127 & $\begin{array}{l}(0.777, \\
1.633)\end{array}$ & 0.529 & 1.872 & $\begin{array}{l}(1.127, \\
3.110)\end{array}$ & 0.015 \\
\hline Donor age & 1.011 & $\begin{array}{l}(0.999, \\
1.024)\end{array}$ & 0.075 & 1.021 & $\begin{array}{l}(1.004, \\
1.039)\end{array}$ & 0.017 \\
\hline $\begin{array}{l}\text { Cold ischaemic } \\
\text { time }\end{array}$ & 1.001 & $\begin{array}{l}(1.000, \\
1.001)\end{array}$ & $<0.001$ & 1.00 & $\begin{array}{l}(1.000, \\
1.001)\end{array}$ & 0.112 \\
\hline
\end{tabular}

Figure 3: Multivariate survival analysis table of significant variables compared to smoking status.

\section{Conclusion}

- Recipient smoking status does not influence overall graft or patient survival following simultaneous kidney pancreas transplant.

- However, there are a cohort of patients for which smoking at the time of transplant is associated with a higher mortality or diminished graft survival.

- Smoking over the age of 55 may be considered a relative contraindication to pancreas transplantation.

\section{Acknowledgements}

The would like to thank NHSBT for providing the data for this study. The research was funded by the National Institute for Health Research Blood and Transplant Research Unit in Organ Donation and Transplantation at Newcastle University in collaboration with University of Cambridge.

The views expressed are those of the author(s) and not necessarily those of the NHS, the NIHR, the Department of Health or NHSBT. 